\title{
Assessing Quality Assurance Practices in Institutions of Higher Learnings
}

\author{
De-Graft Johnson Dei ${ }^{*}$ \\ Department of Information Studies \\ University of Ghana, Legon
}

\begin{abstract}
In the effort to globalize higher education services and embark on innovative knowledge production and dissemination aimed at fitting into the global scheme, quality assurance becomes the sine qua non. Quality assurance (QA) provides the tools and direction to improve the quality of knowledge created, stored and shared at institutions of higher learning. This study assesses the development and practice of QA in institutions of higher learnings (IHLs) in Ghana. The mixed research method was used to collect data from staff and officers of institutions of higher learning who are directly involved ensuring quality in the institutions. Six (6) IHLs participated in this study. The results indicated a generally higher degree of awareness and understanding of the concept of QA at the institutions as all of them have QA department. The institutions are putting in more effort to ensure quality by carrying out internal assessment as there are available policies and strategies aimed at ensuring quality at the institutions. This led to high service quality at the institutions except for the college of health. Besides, the focused areas quality at the institutions: stated vision, mission; governance structure; statutes and conditions of service; academic and programs; clean and siren environment; staffing; and library, technology and information services. Despite these, the study established that the quality assurance units of the institutions lacked the necessary resources (technology, library, staff, laboratories, etc) for effective quality assurance activities.
\end{abstract}

Keywords: Quality; Quality Assurance; Accreditation; Assessment; Audit; Accreditation; Institutions of Higher Learning.

\section{Introduction}

Organizations function as either production-based, service-based, or a hybrid (both service and production) based organizations. Service-based organizations such as institutions of higher learning (IHL) provide intangible products/items (products with no physical form). IHLs generally operates in knowledge and information-based environment. IHLs continue to embrace a series of activities

* Correponding author: De-Graft Johnson Dei, email: djdei@ug.edu.gh 
to meet the needs of their stakeholders and the communities they serve. The objectives of this series of activities are geared toward the satisfaction of their stakeholders effectively and efficiently (Anduvare, 2015).

A promising direction towards the maximization of potentials and drive for improvement is the application of quality assurance (QA) principles. QA is the sine qua non and facilitates the globalization of higher education services and to embark on innovative knowledge production and dissemination aimed at fitting into the global knowledge economy. QA has thus become the fundamental strategy adopted by IHLs in ensuring quality and in achieving their objectives (teaching, research, and innovation). IHLs have adopted QA as the sure way for quality improvement (Yankson, 2013). QA provides the direction to ensure and improve the quality of knowledge creation, processing, storage, and sharing at IHLs. Also, QA ensures that the entirety of topographies and characteristics of services rendered by IHLs meets the recommended international standard and satisfy explicitly outlined or implied needs of their stakeholders (Seniwoliba \& Yakubu, 2015).

According to Yankson (2013), reasons for the growing concern for QA in Ghana are the multiplicity of IHLs in recent times and the explosion in enrolment figures without a commensurate increase in resources and infrastructure. An increasingly heterogeneous population of students adds a different breadth to the debate of quality in IHLs (Krempkow, Pohlenz, \& Huber 2015). These have serious implications for quality at the IHLs. For many staff (academic and nonacademic) and other stakeholders, however, the swiftness and impact of the increasing students' population have been more challenging and has been more of a burden on the IHLs than an opportunity. As a result, QA practices and systems have become an issue of debate and surest way of ensuring quality in IHLs.

There are also concerns concerning

- the increasing overheads on IHLs;

- the continues request and demand by patrons for quality, and better services;

- growing competitions within the academic and educational environment for students and limited resources;

- the tensions between effectiveness, quality, and efficiency;

- growing demand from the public for the accountability of IHLs.

This requires concerted action by all the stakeholders in the education sector of Ghana through QA mechanisms aimed at enhancing the academic and general performance of IHLs in Ghana.

Theoretically, several studies on QA practices have been conducted (Nguyen, 2016; Banji, 2014; Geda, 2014; Marvil, 2013; Maniku, 2008; Lucket, 2006). In Ghana, there have been some studies on QA (Swanzi, 2015; Seniwoliba, 2015; Bosu \& Amayi, 2014; Pongo, Asare \& Abdul-Fatahi, 2015). However, most of them focus on sections of IHLs such as private IHLs (Tsevi, 2014; Asare \& Abdul-Fatahi, 2015), individual universities (Anane \& Addane, 2016; Swanzi, 
2015), technical universities (Okae-Adjei, 2016) among others. The researcher is yet to find any empirical study that sought to assess QA practices in IHLs in Ghana by considering the various categories IHLs and conduct a comparative analysis of QA practices among the various IHLs in Ghana.

It is against this background that this study assessed the QA practices and the mechanisms that the IHLs can implement to ensure quality at the institutions. This study also sought to identify the level of awareness of QA among the staff at the IHLs; application of QA in IHLs; and the impact of QA on IHLs and effective information and knowledge delivery.

\section{Literature review}

This section defines the various terms used in this study. It focused on quality, QA, and QA approaches accreditation, assessment, and audit.

\subsection{Quality}

According to Broucker, Bruno \& Kurt de Witt (2015), the quality of teaching and learning in IHLs have become key strategic issues and concerns across the globe for decades. The term quality originated from the manufacturing and production sector in the early 1980s and descended into the educational domain. Just like "beauty", quality is subjective and a matter of personal judgment (Atsu, 2015). Atsu (2015) and Beerkens \& Udam (2017) further opined that the concept of quality is a concern with the value of judgment. However, many stakeholders in the educational sector such as students, staff (teaching and non-teaching staff) administrators, sponsors, employers, accreditation bodies, government, view and interpret quality differently based on their needs and perception (Singh \& single, 2018).

Quality can be measured from three main approaches: institutional, program and accreditation. Tsevi (2014) measured QA from both institutional and accreditation viewpoint and concluded that QA has truly brought the quality of academic work to accredited private institutions (universities) in Ghana. Tsevi (2014) therefore implored the national accreditation board (NAB), Ghana, to continue to play its critical role as watchdogs and gatekeepers in the educational setup of Ghana. Boateng (2014) also examined the perception of staff and students on national QA issues. Boateng's (2014) findings were that for private tertiary institutions in Ghana to develop the culture of quality, they should instill the philosophies of openness, trust, transparency, responsiveness, and ingenuity.

Mishra (2007) and Dei (2015) posit that the culture of IHLs is with quality and argued that the term quality is:

1. Absolute and considered as the maximum possible criteria or standard;

2. Relative: comparatively described in relative terms;

3. A process that outlines the procedures, requirement, and outcome of a system;

4. Culturally centered and recognizes the significance of the organizational and societal view of quality as a means of transformation where the 
various entities and elements are recognized and acknowledge the relevance of quality

Watty (2003), Harvey (2019), and Badran, Baydoun \& Hillman (2019) also indicate that in considering quality in IHLs, five basic things need to be followed. These are

1. Exceptional: distinguishing, embodies in brilliance and meeting basic laid down standards of academic accomplishment.

2. Perfection or consistency: zero defects, flawless outcome, attaining perfection from the first time by focusing on the process as opposed to just the input and output

3. Fit for purpose and relates to the quality of purpose defined by the provider. That is, it is a concern with the extent to which IHLs can meet their set standards and fulfilling their stated mission and vision.

4. Fulfilling value for money by focusing on efficiency and effectiveness and reassuring output against input.

5. Value for money: a focus on efficiency and effectiveness, measuring outputs against inputs. A populist notion of quality (government). This suggests a ratio between students and teachers. This enhances transparency and better fund management.

6. Transformation: consistent value addition and a qualitative change through teaching and learning. This concept ensures the qualitative and consistency in the enhancement, empowerment, and development of learning and knowledge generation.

\subsection{Quality assurance}

There have been several studies and literature on QA over the years. Some of these studies suggest that QA does not empirically suggest or reflect the quality of teaching. As a result, this cannot be used as the basis for decision making by the management of IHLs and the need to deploy systems in ensuring quality.

According to Tsevi (2014 and Boatent (2014), QA is concerned with a planned, systematic, and sustained review of the procedures and processes of an establishment or institution to ascertain whether or not the established or laid down standards of teaching, assessment, research, innovation, scholarship, and infrastructure are been met or otherwise. It is instigated and carried out with the intent and purpose of maintaining and improving the quality requirement of an institution or program (Badran et al. 2019; Hayward 2001). In this study, QA is defined as

The systematic process of assessing and verifying inputs, outputs and outcomes against standardized benchmarks of quality to maintain and enhance quality, ensure greater accountability and facilitate harmonization of standard across all academic programs, institutions, and systems.

QA embodies and appropriates academic and professional communities (Rosa \& Amaral, 2017; Hopbach, 2014). However, the fitness of purpose in IHLs varies tremendously from one IHL to the other and from program to program. In Ghana, quality in IHLs include the core vision and mission statement; talent, expertise and qualifications of staff (teaching and non-teaching); admission 
requirements; research output; assessment standards, curricula, and teaching methodology; teaching environment; quality laboratories, library, information resources and databases; ICT and technological advancement; physical infrastructure; employability of the graduates; and the governance, leadership and management effectiveness.

QA can take many forms, extending from simple internal or self-assessment to more wide-ranging inspection, supervision, accreditation, external review or audit(s), external and independent peer review, inter-faculty lectures among others (Ayisai, 2015). Conversely, some of the arguments against QA relates to the pedagogy of teaching which is not measurable and cannot be broken down into units, cause-effect relationship. That is the kind of impact by teachers and academic staff on the students learning achievements. (Beerkens \& Udam 2017) However, Atsu (2015) posits that even if quality cannot be readily and easily defined, that does not mean quality cannot be measured although it is not an easy task. This is mainly because the concept of quality is defined by many scholars from their academic and environment

\subsection{Accreditation}

The concept of accreditation varies from country to country. Generally, it is a process which involves an internal and external approach to quality review used in IHLs to assess or evaluate the quality standard of institutions or academic program and the need for action or improvement (Hopbach, 2014; Endut, Majid, Ibrahim, \& Asari, 2013). Seniwoliba \& Yakubu (2015) and Badran et al. (2019) also indicate that, accreditation seeks to evaluate an institution and/or academic program(s) to determine whether laid down standard or threshold is met or qualifies for a certain standard set by established or regulatory bodies such as the government, national QA, professional association, etc. The process is both internal and external which may include self-evaluation, peer review, site visit among others.

In Ghana, accreditation is a widely and mandatory process and requirement for all IHLs. The accreditation of the IHLs with their program is a must. Different bodies are established to facilitate the accreditation of institutions and programs in Ghana. Professional programs such as law, nursing, medicine, etc must also be accredited by the professional body before the program can be organized or run. Successfully meeting the laid down standards will result in the accreditation of the program(s) and/or institution. The process of accreditation involves an assessment and audit.

Assessment is an evaluation and graded (numeric, literal or descriptive) judgment about quality. It goes beyond accreditation that only focuses on binary judgment (Seniwoliba \& Yakubu, 2015). According to Yankson (2013), assessment seeks to answer the question about the outputs of a more quantitative organization. Assessment of programs and institutions are one of the most frequently used method in QA processes in IHL in Ghana. The assessment may be internal and external (Quist, 2016). 
The process of external assessment of programs and institutions in Ghana is established and regulated by the National Accreditation Board (NAB). According to the NAB standard, the procedures include:

1. Obtaining and answering or filling of NAB questionnaires on institutional and program accreditation. The NAB questionnaire can be obtained from the NAB website (NAB/INFO A.1)

2. Submission of the filled NAB questionnaire with the relevant supporting documentation such as a self-assessment form

3. NAB officials conduct a preliminary evaluation of the submitted and filled questionnaires by the institution seeking accreditation.

4. A visit by the NAB officials (mainly made up of experts such as academic and structural experts) to the site or institution seeking accreditation.

5. NAB issues a report on the evaluation after the site visit which includes decisions taken, suggestions and recommendations within 60 calendar days to the institution seeking accreditation;

6. The institution seeking accreditation may apply for a review within 15 calendar days if the report from NAB is not favorable to them

7. NAB sends a final report to the Ministry of Education, Ghana, concerning the progress of work and accreditation of an IHL by the law (LI 1700/20)

Another element of accreditation is "audit". Atsu (2015) \& Hopbach (2014) posit that audit is a systematic and independent assessment or examination of books, accounts, documents, records, and vouchers of an organization to their fairness, accuracy, and truthfulness. In academia, an audit is a process of appraising or scrutinizing the program(s) of an academic institution or the academic institution itself to determine if the curriculum, staff (teaching and nonteaching), infrastructure and other facilities meet the stated standard and objectives or not. An academic audit is carried out at the institutional level. It may be internal and/or external. It usually evaluates the institution and/or its programs about its mission, goal and stated standards (Rosa \& Amaral, 2017).

In Ghana, the accreditation and mentoring institutions do conduct audits on their mentee IHL to ensure the standard. NAB conducts a regular audit on IHLs. An audit focusses on the accountability of institutions and programs and usually involves a self-study, peer review, and a site visit. Such an evaluation can be self-managed or conducted by an external body.

\subsection{Institutions of higher learnings in Ghana}

The emergence of IHLs in Ghana could best be described as an "artifact of colonial policies" (Lulat, 2003). Ghana first tasted formal IHLs in 1948 when the then British Colonial Government established the University College of the Gold Coast as a college of the University of London.

IHLs in Ghana usually refers to universities, colleges, technical universities, polytechnics, and post-secondary specialized educational institutions such as the military and police academy, technical and vocational training centers, etc. It generally begins after the successful completion of senior secondary/high education. IHLs perform the functions of teaching, training, research, and 
services. The mission(s) statements and goals of each IHL articulate their core mission(s). Each institution's programs of study attempt to translate these core missions into achievable goals for its students (http://www.nab.gov.gh).

The National Accreditation Board (NAB) of Ghana is a Government of Ghana's agency and under the Ministry of Education, responsible, among other things for the accreditation of both public and private institutions with regards to contents and standards of their programs and also to determine, in consultation with the appropriate institutions or body, the program and requirements for the proper operation of their institution and the maintenance of acceptable levels of academic or professional standards. It is also responsible for the determination of equivalences of diplomas, certificates and other qualifications awarded in Ghana and elsewhere. NAB categorizes tertiary institutions into the following:

1. A University: An educational institution designed for advanced instruction and research in several branches of learning, conferring degrees in various faculties, and often embodying colleges, schools, and similar institutions.

2. University College: An institution of higher learning that is affiliated to a university and that offers instructions based on programs approved by the university to which it is affiliated and whose degrees/diplomas/certificates are awarded by the parent university.

3. Polytechnics/Technical Universities: An institution of higher or further education in which courses in a large range of subjects, especially, of a technical or vocational kind are available.

4. College: An establishment for further or higher education in the liberal arts (Pure Science/Humanities) or professional studies, sometimes, part of a university, e.g. Business College; College of Music; Naval College.

5. School: An educational institution devoted to a special branch of higher education, e.g. School of Education, School of Economics, School of Medicine, School of Law.

6. Institute: An establishment offering advanced courses in the professions, or the arts, or science and technology.

7. Academy: A place of study or training in a special field, e.g. Military Academy, Academy of Dance, Maritime Academy.

8. Tutorial College: An institution which prepares students to take the examinations of a university or a recognized professional body (http://www.nab.gov.gh).

As at July 2019, IHLs in Ghana stands at one hundred and forty-one (172) comprising fourteen (14) public/government universities, eleven (11) professional public universities, two (2) regional university, three (3) chartered private universities, and eighty-one (81) university colleges affiliated to the public/government universities in Ghana and/or outside Ghana. Additionally, there are two (2) polytechnics, eight (8) technical universities, thirty-eight (38) colleges of education, sixty-six (66) colleges of health, fifteen (15) professional colleges, nineteen (19) tutorial colleges, two (2) distance learning centers, eleven (11) foreign universities, and other specialized institutions such as the Ghana Police Command and Staff College (GPCSC), Ghana Armed Forces Command 
and Staff College (GAFCSC) etc. Every year, these tertiary institutions enroll over 100,000 students in undergraduate, post-graduate, certificate, and diploma programs in a full range of academic and professional fields (http://www.nab.gov.gh).

\section{Research methodology}

The exploratory research was deployed in this study as a means of finding out what is happening at the IHLs in Ghana, seeking new insight, asking questions and assessing phenomenon in a new light (Reiter, 2017). The study explored the efforts and other issues associated with the development and implementation of QA in IHLs in Ghana. The use of exploratory research in this study involved the review of relevant literature in the field of quality and QA (Swedberg, 2018). The choice of exploratory research in this study enabled the research to find out what is happening; seek new insights; ask questions and assess phenomena in a new light concerning QA practices at the IHLs in Ghana.

Furthermore, the mixed (qualitative and quantitative) research method was applied in this research. The use of mixed research for this study is justified by Creswell \& Plano Clark (2018) and Creswell (2014) as it increases the perceived quality of the research, especially when the qualitative study follows the quantitative and provides validation for the findings. However, the researcher placed more emphasis on qualitative research to aid data collection and analysis than the quantitative study (Creswell \& Hirose, 2019). Again, the researcher made use of survey research since the study involved a large and geographically dispersed population. The researcher adopted the survey research since crosspopulation generalizability is a key concern for the study and allowed for a range of educational contexts and subgroups to be sampled (Creamer, 2018).

The general population for this study comprised all the categories (public universities, private universities, technical universities, colleges of education, colleges of health, and tutorial colleges) of the IHLs in Ghana. Out of these, the researcher purposively selected one IHL from each category to represent the specific population for this study. From each category of IHL, the researcher again used the purposive sampling technique to select a sample of 8 staff to serve as respondents for this study. These include the Registrar, QA officer or Head of QA unit, Librarian, Head of Department, and 4 lecturers. These selected respondents are the officers whose activities are mainly directed towards ensuring quality in IHLs. Therefore, a total of 48 respondents participated in this study. The purposive sampling technique was adopted due to the unique character of the respondents and enabled the respondents to answer the questions. It enabled the researcher to reach the targeted sample quickly and since proportionality is not the main concern.

Data were collected from both primary and secondary sources. Primary data was collected with the use of questionnaires (consisting of both closed and openended questions). Secondary data consisted of a review of QA reports and feedback documents from NAB and internal assessments, NAB published documents and other government and academic papers on higher education as 
well as other forms of published documents related to the topic. The researcher ensured that reliability was achieved by ensuring that the questionnaire distributed to the respondents had the same set of questions.

Data analysis went through two main stages. The first stage was the data preparation which involved organizing, piling up, typing field-notes and recordings, and sorting the data. The second component was the analysis itself where the researcher analyzed the data by coding the refined (prepared) data and made it ready for analysis.

\section{Presentation and discussion of findings}

This section presents the results and findings of the data obtained from the reviewed documents as stated in the methodology and interviews conducted for this study. The presentation of the collected data was based on the stated objectives of the study.

\subsection{Familiarity and understanding of the concept of quality and QA at the}

IHL

The results from the analyzed data indicated that there is a general high level of familiarity and understanding of the concept of quality and QA with a 100\% affirmation rate. It would have been very difficult to proceed with the study should their level of understanding not been confirmed to be positive. Their responses are presented in the table below.

Table 1: Familiarity, Availability, Qualification of Quality Assurance Officers

\begin{tabular}{|c|c|c|c|c|c|c|c|c|}
\hline \multirow{2}{*}{\multicolumn{2}{|c|}{ Responses }} & \multicolumn{3}{|c|}{ Universities } & \multicolumn{3}{|c|}{ Colleges } & \multirow[b]{2}{*}{ Net } \\
\hline & & Public & Private & Technical & Health & Education & Tutorial & \\
\hline \multirow{2}{*}{$\begin{array}{c}\text { Understanding } \\
\text { of the concept } \\
\text { of quality and } \\
\text { QA }\end{array}$} & Yes & $\begin{array}{c}8 \\
(100 \%) \\
\end{array}$ & $\begin{array}{c}8 \\
(100 \%) \\
\end{array}$ & $\begin{array}{c}8 \\
(100 \%) \\
\end{array}$ & $\begin{array}{c}8 \\
(100 \%) \\
\end{array}$ & $\begin{array}{c}8 \\
(100 \%) \\
\end{array}$ & $\begin{array}{c}8 \\
(100 \%) \\
\end{array}$ & $\begin{array}{c}48 \\
(100 \%) \\
\end{array}$ \\
\hline & No & $\begin{array}{c}0 \\
(00 \%)\end{array}$ & $\begin{array}{c}0 \\
(00 \%)\end{array}$ & $\begin{array}{c}0 \\
(00 \%) \\
\end{array}$ & $\begin{array}{c}0 \\
(00 \%) \\
\end{array}$ & $\begin{array}{c}0 \\
(00 \%) \\
\end{array}$ & $\begin{array}{c}0 \\
(00 \%) \\
\end{array}$ & $\begin{array}{c}0 \\
(00 \%) \\
\end{array}$ \\
\hline \multirow[b]{2}{*}{$\begin{array}{c}\text { Available QA } \\
\text { units }\end{array}$} & Yes & $\begin{array}{c}8 \\
(100 \%)\end{array}$ & $\begin{array}{c}8 \\
(100 \%)\end{array}$ & $\begin{array}{c}8 \\
(100 \%)\end{array}$ & $\begin{array}{c}6 \\
(75 \%) \\
\end{array}$ & $\begin{array}{c}6 \\
(75 \%)\end{array}$ & $\begin{array}{c}3 \\
(37.50 \%)\end{array}$ & $\begin{array}{c}39 \\
(81.25 \%)\end{array}$ \\
\hline & No & $\begin{array}{c}0 \\
(00 \%)\end{array}$ & $\begin{array}{c}0 \\
(00 \%)\end{array}$ & $\begin{array}{c}0 \\
(00 \%)\end{array}$ & $\begin{array}{c}2 \\
(25 \%)\end{array}$ & $\begin{array}{c}2 \\
(25 \%)\end{array}$ & $\begin{array}{c}5 \\
(62.50 \%)\end{array}$ & $\begin{array}{c}9 \\
(18.75 \%)\end{array}$ \\
\hline \multirow{2}{*}{$\begin{array}{c}\text { Qualified and } \\
\text { experienced } \\
\text { QA officers }\end{array}$} & Yes & $\begin{array}{c}8 \\
(100 \%)\end{array}$ & $\begin{array}{c}5 \\
(62.50 \%)\end{array}$ & $\begin{array}{c}6 \\
(75 \%) \\
\end{array}$ & $\begin{array}{c}2 \\
(25 \%) \\
\end{array}$ & $\begin{array}{c}2 \\
(25 \%)\end{array}$ & $\begin{array}{c}2 \\
(25 \%)\end{array}$ & $\begin{array}{c}25 \\
(52.08 \%)\end{array}$ \\
\hline & No & $\begin{array}{c}0 \\
(00 \%)\end{array}$ & $\begin{array}{c}3 \\
(37.50 \%)\end{array}$ & $\begin{array}{c}2 \\
(25 \%)\end{array}$ & $\begin{array}{c}6 \\
(75 \%) \\
\end{array}$ & $\begin{array}{c}6 \\
(75 \%)\end{array}$ & $\begin{array}{c}6 \\
(75 \%) \\
\end{array}$ & $\begin{array}{c}23 \\
(47.92 \%)\end{array}$ \\
\hline \multirow[b]{2}{*}{$\begin{array}{c}\text { Dedicated QA } \\
\text { officers }\end{array}$} & Yes & $\begin{array}{c}8 \\
(100 \%) \\
\end{array}$ & $\begin{array}{c}6 \\
(75 \%) \\
\end{array}$ & $\begin{array}{c}8 \\
(100 \%) \\
\end{array}$ & $\begin{array}{c}2 \\
(25 \%) \\
\end{array}$ & $\begin{array}{c}2 \\
(25 \%) \\
\end{array}$ & $\begin{array}{c}1 \\
(25 \%) \\
\end{array}$ & $\begin{array}{c}15 \\
(12.50 \%)\end{array}$ \\
\hline & No & $\begin{array}{c}0 \\
(00 \%) \\
\end{array}$ & $\begin{array}{c}0 \\
(25 \%) \\
\end{array}$ & $\begin{array}{c}0 \\
(00 \%) \\
\end{array}$ & $\begin{array}{c}6 \\
(75 \%) \\
\end{array}$ & $\begin{array}{c}6 \\
(75 \%) \\
\end{array}$ & $\begin{array}{c}7 \\
(75 \%) \\
\end{array}$ & $\begin{array}{c}9 \\
(87.50 \%) \\
\end{array}$ \\
\hline
\end{tabular}

Source: Field data, 2019

One of the most effective and efficient means of improving and ensuring quality in IHL is the establishment of a QA unit that will be responsible for the institutional wide QA process and management. The study revealed that apart from the tutorial college $(37.50 \%)$, the rest of the IHLs have QA unit $(81.25 \%)$. 
This finding is consistent with the directive from NAB to all IHLs in Ghana to establish internal QA units or systems for internal quality management with the hope that all the staff of the institution will support the internal structures and requirements. The result from the tutorial college calls for a swift action thereby setting up QA unit. The QA units at the IHLs are set up to ensure that all the academic activities in the institution and the institution itself become responsible for their own QA practices and procedures. The internal QA unit facilitates the internal QA systems of the IHLs; ensure the assurance of the IHLs to constantly screen and increase their QA practices and also to ensure that standards are always maintained.

Besides, the general indication is that the IHLs in Ghana have qualified officers with the right qualification (researched degree) to be in charge of QA issues. However, while the universities (public, private and technical) have QA officers possessing research degrees with vast experience in teaching and research at the tertiary level as recommended by $\mathrm{NAB}$, the QA officers at the colleges (education, health, and tutorial) do not have research degrees. These responses were supported by the documents made available to the researcher during data collection. The study again showed that the universities (public, private and technical) have dedicated officers to superintend QA issues at the universities. Their core job description is to ensure quality at the universities. On the other hand, the colleges (education, health, and tutorial) do not have dedicated officers to ensure quality at the institutions. Their QA officers are mainly tutors with additional responsibilities as QA officers.

\subsection{Quality assurance policy and carrying out internal academic self- assessment}

Another effective means of by which IHLs can manage and ensure quality is by establishing effective internal policies and self-assessment. (Stensaker, et al., 2008). The study established that the IHLs were putting in more efforts (54.17\%) to ensure quality by carrying out self-regulating institutional and academic assessment. However, at the individual institutional level, apart from the tutorial college $(25 \%)$, all the other IHLs were putting in more effort to ensure quality by carrying out self-regulating institutional and academic assessment. The tutorial college was just reluctant to adhere to the laid down procedures until they are compelled to do so by their supervising institution. The assessment of internal documents at the private university contradicts the responses of the respondents. Whiles they are trying to put in some efforts to ensure quality by instituting internal self-assessment programs, this is not always done as they only do it when instructed or compelled to do so by their supervising institution. This was due to the lack of comprehensive documentation supporting the internal assessment claims by the private university. 
Table 2: Quality assurance policy and carrying out internal academic self-assessment

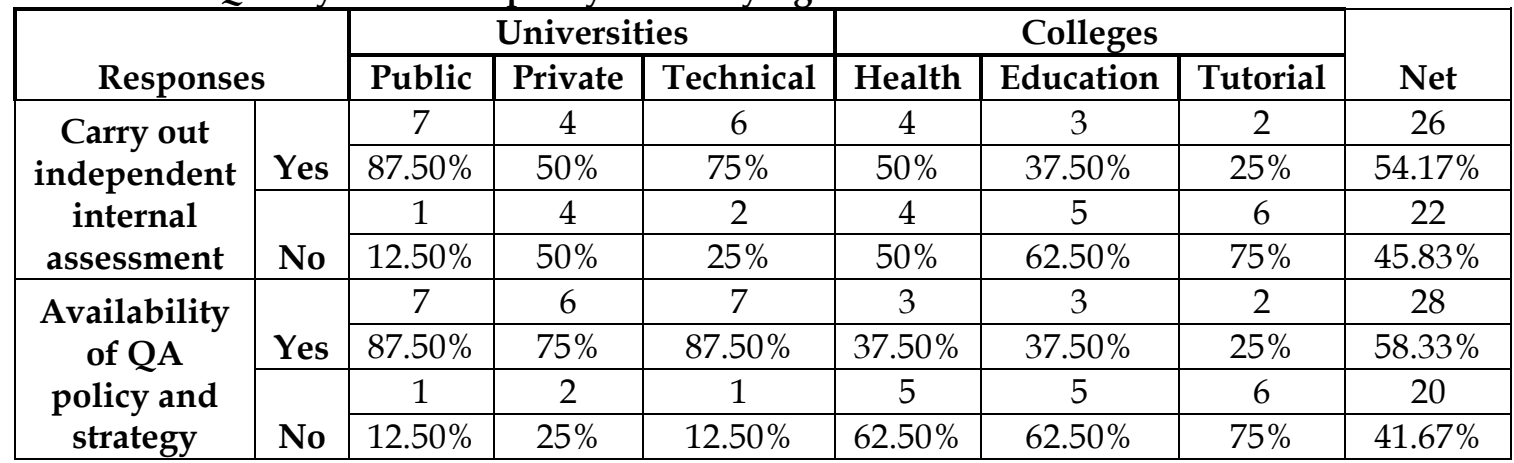

Source: Field data, 2019

QA policies and strategies are established to guide and regulate practices of the institution. This would usually reflect the core mission, vision, and values of the institution. The study established the availability of QA policies and strategies at the IHLs. However, at the individual IHLs, while the colleges established the absence or unavailability of QA policies and strategies (Yes: Health, 37.50\%; Education, 37.50\%; and Tutorial, 25\%), the universities established the availability of policy and strategy on QA (public, $87.50 \%$; private, $75 \%$; and technical, 87.50\%). Qualitative documents available to the researcher also indicated that the colleges (education, health, and tutorial) largely relied on NABs guidelines and directives to ensure quality. They also relied on the QA policy and strategy document by their supervisory or mentoring institutions. The primary objective of a QA policy is to ensure the successful application and deployment of quality practices and standards at the IHLs. The leadership of the IHLs established and agreed on the objectives and goals of QA and how these goals would be pursued within the overall QA framework of the IHLs

The QA process of all new and operating IHLs and programs is compulsory in Ghana. The study revealed that all the IHLs have been accredited. Similarly, they indicated that all the programs they run are accredited by the National accreditation board and their mentoring institutions as indicated by the private universities, colleges (education, health, and tutorial). During the accreditation process, there is an information request for self-evaluation. The available data revealed the focused areas as identified by the respondents:

1. Stated vision, mission, and objectives

2. Governance structure and organogram

3. Statutes and conditions of service

a. Human resource/capital management, appointments and promotion, code of conduct, ethics and action, disciplinary actions, academic, and career progression and administrative leadership

4. Programs and academics

a. admission policy, research output, curriculum, examinations, student affairs and issues, moderation (internal \& external), provision for students assessment of course content and teaching and peer and professional assessment of the content of teaching, and academic regulation 


\section{Staffing}

a. Qualification, experience and job description of all the staff (teaching/faculty and non-teaching/faculty)

6. Physical facilities

a. lecture halls; internet, systems, and technology; library, computer laboratories, workshops; registry and administrative blocks;

\subsection{Available resources to support quality assurance}

The study again established that all the QA units of the IHLs lacked the necessary resources $(45.83 \%)$ to support QA activities. They mention them to include limited staffing, lack of offices and appropriate ICT infrastructure and supporting machines/accessories, inadequate library materials, stationery, etc. However, it was established that the public and technical universities have more resources $(87.50 \%, 87.50 \%)$ than the private university $(75 \%)$. That is, the public and technical universities were more equipped than the other IHLs. Also, aside from the public and technical universities, the resources (staff, offices, and computers) at the other IHLs are very limited. As a result, these institutions failed to effectively ensure quality.

The study again established that the sitting of the lecture halls of the private and technical universities, and colleges (education, health, and tutorial) affected teaching and learning. The respondents express that nearby houses and shops were constantly playing songs and open up their systems beyond the normal level. This introduced a lot of noise and made the learning environment unfavorable for effective academic work such as teaching and learning. Also is the noise emanating from vehicles passing by the institutions.

\subsection{General satisfaction of quality at the IHLs}

The study sought to assess the general level of satisfaction of quality among the staff of the IHLs. The responses shows an even majority $(50 \%)$ of the respondents are pleased with the level of service quality delivery at the IHLs as against $20.83 \%$ and $29.17 \%$ of the respondents who were either neutral in their responses or not satisfied with service quality at the IHLs respectively.

Table 3: General satisfaction of quality at the IHLs

\begin{tabular}{|c|c|c|c|c|c|c|c|}
\hline \multirow{2}{*}{ Responses } & \multicolumn{3}{|c|}{ Universities } & \multicolumn{3}{c|}{ Colleges } & \multirow{2}{*}{ Net } \\
\cline { 2 - 8 } & Public & Private & Technical & Health & Education & Tutorial & \\
\hline \multirow{2}{*}{ Satisfied } & 6 & 4 & 5 & 3 & 3 & 3 & 24 \\
\cline { 2 - 8 } & $(75 \%)$ & $(50 \%)$ & $(62.50 \%)$ & $(37.50 \%)$ & $(37.50 \%)$ & $(37.50 \%)$ & $(50 \%)$ \\
\hline \multirow{2}{*}{ Neutral } & 1 & 1 & 2 & 2 & 2 & 2 & 10 \\
\cline { 2 - 8 } & $(12.50 \%)$ & $(12.50 \%)$ & $(25 \%)$ & $(50 \%)$ & $(50 \%)$ & $(50 \%)$ & $(20.83 \%)$ \\
\hline \multirow{2}{*}{$\begin{array}{c}\text { Not } \\
\text { Satisfied }\end{array}$} & 1 & 3 & 1 & 3 & 3 & 3 & 14 \\
\cline { 2 - 8 } & $(12.50 \%)$ & $(37.50 \%)$ & $(12.50 \%)$ & $(37.50 \%)$ & $(37.50 \%)$ & $(37.50 \%)$ & $(29.17 \%)$ \\
\hline
\end{tabular}

Source: Field data, 2019

The results point to a high satisfaction level of quality at all the IHLs except the college of health. Similarly, the public university had the highest $(75 \%)$ level of service quality delivery. This might not necessarily mean that the IHLs are fully excellent since it might be possible that there are areas where some of the 
respondents are not satisfied with service quality at the IHLs. This result is consistent with similar findings by Ham and Hayduk (2003) and Elliot and Shin (2002).

The study finally established that ensuring quality at the IHLs calls for the involvement of all the stakeholders of education. It was revealed that quality at the IHLs is not just about teaching. The respondents outlined the following as factors that promote effective QA at the IHLs.

1. Clean and siren environment

2. Qualified and experience:
a. Lecturers/Tutors
b. QA officers
c. Registry and support staff
d. Librarian and supporting staff

3. Available and accessible:
a. Library and information services
b. internet facilities
c. computers and other technological facilities

4. Continues capacity building and support for staff (teaching and nonteaching)

\section{Conclusion}

This study assessed the development and practice of QA in IHLs in Ghana. The results indicated that there is a general high level of familiarity and understanding of the concept of quality and QA at the IHLs as all of them have QA departments. However, while the universities have qualified and experienced QA officers as recommended by NAB, the QA officers at the colleges do not have research degrees, thus not qualified to head QA units. The study again established that the IHLs were putting in more efforts to ensure quality by carrying out internal assessment as there were available QA policies and strategies at the IHLs. This led to high service quality at all the IHLs except the college of health. Comparatively, QA practices at the universities were seen to be better than the colleges. Also, the result revealed the focused areas for accreditation process to include: stated vision, mission, and objectives; governance structure and organogram; statutes and conditions of service; academic and programs; and staffing. The rest include a clean and siren environment; qualified and experienced staff; available and accessible library, technology and information services.

Despite these, the study established that the QA units of the IHLs lacked the necessary resources to support QA activities. In addition, the sitting of the lecture halls of the private and technical universities, and colleges affected quality of teaching and learning as nearby houses and shops were constantly playing songs and open up their systems beyond the normal level and the noise emanating from vehicles passing by the institutions introduced a lot of noise and made the learning environment unfavorable for effective QA practice such as teaching and learning. 


\section{Research implications}

In ensuring and improving academic quality and upholding institutional improvement, QA and academic planning are a critical success factor for all IHLs. Moreover, government legislation is increasingly making IHLs in Ghana more accountable for the quality of teaching and learning, and the relevance of their degrees and diplomas. This has numerous implications for all IHLs to effectively put in place adequate measures to carry out the mandate of quality assurance.

It has been established in this study that not all the IHLs have QA units, officers, and policies in place. The regulatory body and policy-making agencies such as: the Ministry of Education, National Accreditation Board (NAB), National Council for Tertiary Education (NCTE), Council for Technical and Vocational Education and Training (COTVET), Vice-Chancellors Ghana and the Universities' Councils need to take practical steps to ensure the enhancement of the implementation of QA units and employ qualified and dedicated QA officers at the various IHLs in Ghana.

Also, QA plays a critical role in IHLs. The leadership of the IHLs should improve on the awareness, adoption, and practice of QA at the IHLs to facilitate competitive advantage. This can be done by inculcating QA practices into the IHLs program where staff (teaching and non-teaching) will be given training on the role of QA and the need to ensure quality at the IHLs in their day-to-day activities.

\section{Recommendation}

Based on the findings and conclusion, the researcher makes the following recommendations.

1. Since the study established the absence of qualified staff as QA officers at the colleges (health, education, and tutorial), it is therefore recommended that the colleges should appoint qualified and experienced officers to be in charge of the QA units. The technical universities and private universities should also put in efforts to employ qualified and experienced people as QA officers

2. It is also recommended that the colleges without QA units should also set up QA units to holistically ensure quality at their institutions.

3. The colleges also need to employ dedicated officers to serve as QA officers. The absence of dedicated QA officers at the colleges will then facilitate and ensure quality at the colleges.

4. Since the study established the absence of QA policies and strategies at the IHLs, especially at the colleges, the researcher, therefore, recommends that the IHLs should develop QA policies and strategies at their institutions. Should the IHLs (especially the colleges) set up QA units and employ qualified, experienced, dedicated QA officers, they will fast-track the development of the QA policies and strategies.

5. Mentoring and NAB should enhance the monitoring and supervisory work at the IHLs 
6. The management of the IHLs should invest in technology, library, computer laboratories, staffing, etc to produce quality at the IHLs

\section{References}

Anduvare, E. M. (2015). Developing a knowledge management strategy for the Marist International University College, Nairobi-Kenya. Pretoria: Unisa press.

Asiyai, R. I. (2015). Improving Quality Higher Education in Nigeria: The Role of Stakeholders. International Journal of Higher Education, 4(1), 61-70. http://dx.doi.org/10.5430/ijhe.v4n1p61

Atsu, N. S. (2015). Quality Assurance Practices in Private Universities in the Greater Accra Region of Ghana. Cape Coat: University of Cape Coast.

Badran, A. A., Baydoun, E., \& Hillman, J. R. (Eds). (2019). Major Challenges Facing Higher Education in the Arab World: Quality Assurance and Relevance. Switzerland: Springer Nature.

Becket, N., \& Brookes, M. (2008). Quality Management Practice in Higher EducationWhat Quality Are Actually Enhancing? Journal of Hospitality, Leisure, Sport and Tourism Education, 7(1): 40-54. http://dx.doi.org/10.3794/johlste.71.174

Beerkens, M., \& Udam, M. (2017). Stakeholders in higher education quality assurance: Richness in diversity? Higher Education Policy, 30(3), 341-359. http://dx.doi.org/10.1057/s41307-016-0032-6

Boateng J. K. (2014). Barriers to Internal Quality Assurance in Ghanaian Private Tertiary Institutions. Research on Humanities and Social Sciences, 4(2).

Council for Higher Education Accreditation (CHEA) (2010). The value of Accreditation. http://www.chea.org/pdf/stmntstudentlearningoutcomes

Creamer, E. G. (2018). An introduction to fully integrated mixed methods research. Thousand Oaks, CA: Sage Publications.

Creswell J. W., \& Plano Clark V.L. (2018). Designing and conducting mixed methods research (3rd ed.). London: Sage Publications.

Creswell, J. W. (2014). Research Design: Qualitative, Quantitative and Mixed Methods Approaches (4th ed.). London: Sage Publications Ltd.

Creswell, J. W., \& Hirose, M. (2019). Mixed methods and survey research in family medicine and community health. Family Medicine and Community Health. http://dx.doi.org/10.1136/fmch-2018-000086

Dei, D. J. (2017). Assessing Knowledge Management Systems in Ghanaian Universities. Proceedings of the International Conference of Entrepreneurship, Business and Technology, 24-35.

Doherty G. D. (2008). On Quality in Education. Quality Assurance in Education, 16(3), 225226. https://doi.org/10.1108/09684880810886268

Endut A. S., Majidb, F. A., Ibrahimc, A. B., \& Ashari, H. (2013). Responsive Outcome Evaluation as an Internal Quality Assurance Mechanism Alternative at IHLs in Malaysia. Procedia - Social and Behavioral Sciences, 90, 13-21. http://doi.org/10.1016/j.sbspro.2013.07.060

European Commission/EACEA/Eurydice (2018). The European Higher Education Area in 2018: Bologna Process Implementation Report. Luxembourg: Publications Office of the European Union.

Harvey, L. (2019). Analytic Quality Glossary. Quality Research International. Available at: http://www.qualityresearchinternational.com/glossary/

Hopbach, A. (2014). Recent trends in quality assurance? Observations from the agencies' perspectives. Basingstoke: Palgrave.

Konrath, L. F. (2002). Auditing: a Risk Analysis Approach (11 ${ }^{\text {th }}$ ed.). London: Thomson. 
Mishra S. (2007). Quality Assurance in Higher Education. Bangalore: National Printing Press.

National Accreditation Board (NAB) (2016). Accredited Tertiary Institutions. www.nab.gov.gh/

New England Commission of Higher Education (NECHE) (2016). Standards for Accreditation: New England Commission of Higher Education. New Burlington: NECHE.

Quist, E. L. (2016). Leadership and Quality Assurance of Teaching and Learning. Ghana: Ministry of Education, Ghana.

Reiter, B. (2017). Theory and Methodology of Exploratory Social Science Research. International journal of research and science methodology, 5(4), 125-150.

Rosa, M. J., \& Amaral, A. (2017), Quality Assurance in Higher Education: Contemporary Debates. Basingstoke: Palgrave.

Seniwoliba, A. J., \& Yakubu, R. N. (2014). An analysis of the quality assurance policies in a Ghanaian University. Educational Research and Reviews, 10(16), 2331-2339. http://doi.org/10.5897/ERR2015. 2425

Singh, A., \& Singla, L. (2018). Stakeholders Satisfaction regarding Service Quality in Higher Management Education. International Journal of Management Studies, 3(6), 2231-2356. http://dx.doi.org/10.18843/ijms/v5i3(6)/01

Stamelos, G., \& Kavasakalis, A. (2011). The public debate on a quality assurance system for Greek universities. Quality in Higher Education, 17(3), 353-368. http://doi.org/10.1080/13538322.2011.628807

Swedberg, R. (2018). On the Uses of Exploratory Research and Exploratory Studies in Social Science. Canada: Connell University.

Tammaro A. M. (2005). Report on Quality Assurance models in LIS programs. Available at: http://www.ifla.org/VII/S23/indexhtm

Tsevi L. (2014). Private Higher Education's Quality Assurance in Ghana. International Higher Education, 75, 22-24. http:// doi.org/10.6017/ihe.2014.75.5437

Watty K. (2003). When will Academics Learn about Quality? Quality in Higher Education, $9(3)$.

Yankson, K. (2013). Quality Assurance in Higher Education in a Globalise. Cape Cost: UCC. 